\title{
Natural Lyme disease cycles maintained via sheep by co- feeding ticks
}

\author{
N. H. OGDEN ${ }^{1,2 *}$, P. A. NUTTALL ${ }^{2}$ and S. E. RANDOLPH ${ }^{1}$ \\ ${ }^{1}$ Department of Zoology, University of Oxford, South Parks Road, Oxford OX1 3PS \\ ${ }^{2}$ NERC Institute of Virology and Environmental Microbiology, Mansfield Road, Oxford OX1 3RS
}

(Received 23 April 1997; revised 26 Fune 1997; accepted 26 Fune 1997)

\section{SUMMARY}

We present observational and experimental evidence that cycles of the Lyme disease spirochaete, Borrelia burgdorferi s.l., can be maintained by sheep in the virtual absence of alternative hosts. A 2-year field study in upland moorland habitats of northwest UK established that sheep feed up to $80 \%$ of larval, $>99 \%$ of nymphal and all of the adult female tick (Ixodes ricinus) population. Infection prevalence of B. burgdorferi in questing ticks reaches over $20 \%$, but amplification of infection occurs principally as nymphs (20- to 30-fold), rather than larvae (4- to 7-fold), feed on sheep, and transmission from sheep to ticks occurred only during peak tick abundance in May and September. Experimental transmission studies confirmed that sheep, previously exposed to infected ticks on the moorland site, do not support systemic infections of $B$. burgdorferi, but they can transmit localized infections from infected to uninfected ticks co-feeding at the same site on the sheep's body.

Key words: Lyme borreliosis, ticks, sheep, co-feeding transmission.

\section{INTRODUCTION}

Lyme borreliosis, a zoonosis caused by the spirochaete Borrelia burgdorferi sensu lato transmitted by Ixodid ticks, is the most prevalent and widespread vector-borne infection of humans in the northern hemisphere, a consequence of the enormous diversity of the system that allows the maintenance of enzootic cycles under a wide range of ecological conditions. This diversity is generated by interactions between a number of distinct genetic strains of B. burgdorferi (Postic et al. 1994), a variety of tick species, mostly of the genus Ixodes, and the wide range of vertebrate hosts upon which they feed, an increasing number of which are known to be competent to transmit $B$. burgdorferi s.l.. Despite such diversity, the conventional theory is that enzootic cycles of Lyme borreliosis are driven by small rodents (e.g. mice and voles) (Mather et al. 1989; Jaenson, 1991). These are abundant hosts which each feed moderate numbers of the immature stages (larvae and nymphs) of the principal Ixodes vectors which, in both Europe and the USA, are most commonly found in woodlands (Gray, 1991; Lane, Piesman \& Burgdorfer, 1991). Deer feed large numbers of larval, nymphal and adult ticks and so are essential in maintaining tick populations (Wilson et al. 1998; Jaenson \& Tälleklint, 1992). Indeed, one

* Corresponding author: Department of Veterinary Clinical Science, Faculty of Veterinary Science, University of Liverpool, PO Box 147, Liverpool L69 3BX. Tel: +0151794 6087. Fax: +0151794 6065. E-mail: nogden@liverpool.ac.uk reason given for the recent emergence of Lyme disease is the population explosion of deer (Lane et al. 1991), but both white-tailed deer in the USA and roe deer in Europe are considered to be incompetent as reservoir hosts to B. burgdorferi s.l. (Telford et al. 1988; Jaenson \& Tälleklint, 1992; Matuschka et al. 1993). The perceived enzootic cycle of Lyme borreliosis does not explain field data in the UK: rodents feed so few nymphal Ixodes ricinus that they can only maintain borreliosis cycles on their own if they are infected by transovarially infected larvae (Randolph \& Craine, 1995), but other vertebrates, squirrels and pheasants, have been shown to contribute substantially to the transmission of spirochaetes (Craine, Randolph \& Nuttall, 1995; Randolph \& Craine, 1995; Craine et al. 1997; Kurtenbach et al. 1997).

Besides its woodland habitat, I. ricinus is also abundant on upland moorlands in the north and west of the UK. Here deforestation and the introduction of grazing sheep have resulted in species-poor grassland, in place of the original sessile oak woodland (Pearsall \& Pennington, 1989), where sheep are the most important host for all 3 tick stages (Milne, 1947; Steele \& Randolph, 1985). Despite the paucity of tick host species, there is evidence that enzootic cycles of B. burgdorferi s.l. exist (Ogden, Carter \& Nuttall, 1994) and Lyme disease affects the local inhabitants (O'Connell, 1995). In this study, we investigated the rôle of sheep in the Lyme borreliosis transmission cycle by (i) determining the relative contribution of rodents, birds and sheep to tick feeding, (ii) comparing infection prevalence in 
unfed questing ticks and ticks that had fed on grazing sheep, and (iii) undertaking transmission studies with captive sheep using an entirely natural system.

\section{MATERIALS AND METHODS}

\section{Study site}

Field work was carried out on an enclosed 80 ha region of typical upland moorland (Rodwell, 1994) in Cumbria, northwest UK $\left(2^{\circ} 46^{\prime} \mathrm{W}, 54^{\circ} 31^{\prime} \mathrm{N}\right)$. Sparse relict woodland covered a steep hillside running up to open fell at ca. $500 \mathrm{~m}$ above sea level. A population of 80 Swaledale and Swaledale/Cheviot ewes grazed the fell throughout the year except when removed for short periods for shearing in July and mating in November. Ewes lambed on the site during April, producing 64 lambs which were weaned and removed from the site in August. As the woodland was fenced off midway through 1993 to exclude sheep, the data for this study come principally from the fell, although the numbers of rodents and questing ticks were counted in both habitats for comparison.

\section{Hosts and their tick infestations}

Each month from February 1994 to January 1995 (excluding June, unavoidably), samples of sheep (10 to 174 +year-old ewes and lambs from March to September and 6-8 sheep at other times) were gathered from the fell. The numbers of each stage of I. ricinus feeding on them were counted using a standardized routine. The accuracy of this routine was assessed by exhaustive examinations of 3 ewes and 3 lambs in May under optimum handling conditions and good lighting in a farm building: during the regular surveys in the field most of the nymphs and adults, but only at most one third of the larvae feeding on sheep were counted.

Rodents were trapped using standard procedures (Gurnell \& Flowerdew, 1990). In the woodland, each month from February 1994 to January 1995 two Longworth Humane traps (Longworth Scientific, Abingdon, UK) were placed at each of 16 trap points of a 1 ha grid, pre-baited for 1 night and set to catch over the following 2 nights. Animals trapped on the first night were marked by fur clipping. The same routine on the fell during 1993 yielded very few rodents; in an attempt to improve trapping success in 1994, each month 2 traps were placed at each of 20 points along random $300 \mathrm{~m}$ transects over the site, and at 15 additional points targeted at visible vole runs (total 70 traps). If the traps at each point sampled an area of radius ca. $10 \mathrm{~m}$, each transect would have sampled an area of $300 \times 20 \mathrm{~m}^{2}=0.6 \mathrm{ha}$. Each trapped rodent was examined closely for feeding ticks, paying particular attention to each rodent's head and ears, upon which virtually all I. ricinus feed (Milne, 1949; this study).
Counts of the number of singing, territory-holding male birds, commonly used as an index of density, could have under-estimated bird density as the species commonly found in these upland habitats have a skulking, ground feeding habit, 'sitting tight' on the approach of predators and man (Cramp, 1988). Therefore, counts were made of all birds seen while walking transects through the full range of fell community types over 16 ha: four parallel transects, $400 \mathrm{~m}$ long and $100 \mathrm{~m}$ apart, plus transects perpendicular to these four, were walked on sunny days in June beginning at $07.30 \mathrm{~h}$. A gun dog was used to flush birds from up to $50 \mathrm{~m}$ on each side of each transect.

Larger mammalian wild hosts were searched for, but proved to be extremely scarce. There was a single fox den and a single badger sett in the vicinity of, but not actually within, the study site, in keeping with the normal density of about 1 pair of foxes per $40 \mathrm{~km}^{2}$ and up to 12 adult badgers per $10 \mathrm{~km}^{2}$ on such hill land (Corbet \& Southern, 1977), equivalent to 1 or 2 individuals on the study site. Lagomorphs were never seen at this site.

\section{Infection prevalence in questing and fed ticks}

Questing ticks were counted and collected using standard sampling methods: a $1.6 \mathrm{~m}^{2}$ blanket was dragged over four $25 \mathrm{~m}$ lengths of the vegetation in each part of the site (woodland and fell) each month during 1993 and 1994. Engorged ticks were collected from sheep each time they were examined, on 3 occasions (April, July and September) in 1993 and monthly in 1994. B. burgdorferi s.l. infection in both questing and fed ticks taken from the fell, and in a subset of engorged ticks collected from sheep and allowed to moult, was diagnosed by 2 independent methods. Approximately half of the ticks were examined by the indirect immunofluorescence technique using a 1/20 dilution of a mouse monoclonal H9724 anti-flagellin of $B$. burgdorferi as primary antibody applied to tick material fixed on microscope slides (Livesley et al. 1994). A $1 / 80$ dilution of the secondary antibody (fluorescein isothiocyanatelabelled anti-mouse IgG whole molecule, Sigma) was added and B. burgdorfer $i$ was visualized at $\times 400$ magnification under UV illumination. The remaining ticks were examined by the polymerase chain reaction (PCR) technique. Negative controls, included at a rate of 1 per 3 tick samples, confirmed that carry-over contamination was eliminated. DNA was obtained by phenol/chloroform extraction and ethanol precipitation from guanidinium/2mercaptoethanol thiocyanate-treated, macerated ticks. Extracted DNA was then amplified by a 'nested' PCR using 2 pairs of primers complementary to the gene encoding the outer surface protein $\mathrm{A}$ (OspA) of B. burgdorferi strain B31 (Guy \& Stanek, 1991). Previously optimized cycles produced an 


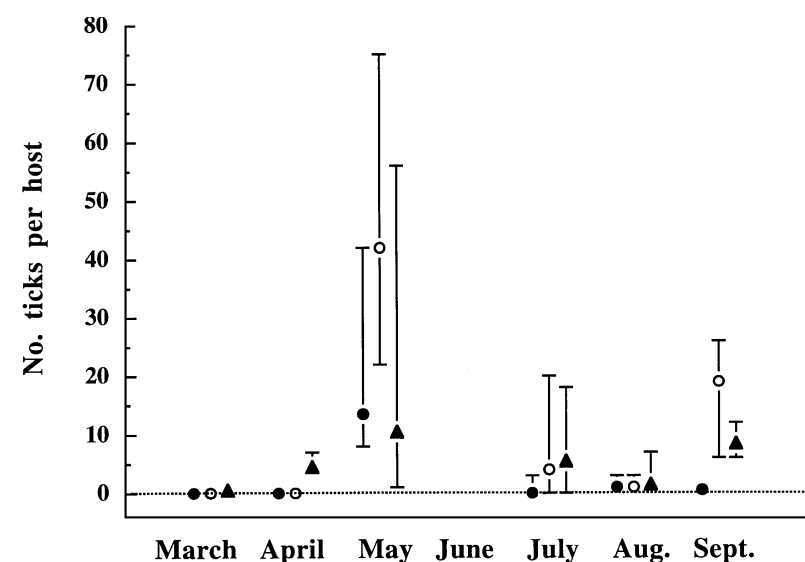

Fig. 1. Seasonal variation in larval $(\mathbf{O})$, nymphal $(\bigcirc)$ and adult $(\mathbf{\Delta})$ Ixodes ricinus infestation levels counted on sheep gathered from the fell (median, with 20 and 80 percentiles). Monthly $n=10-17$. During these regular surveys only about one third of larvae feeding on sheep were counted.

amplified product of 351 base pairs which, following agarose gel electrophoresis and ethidium bromide staining, was visualized under UV light. The limit of sensitivity of the PCR was estimated at 5 organisms per unfed tick, increased to 10 organisms per tick in engorged nymphs and adult females (but not larvae).

\section{Experimental transmission of $\mathrm{B}$. burgdorferi}

Experiments were performed to test the ability of sheep to support transmission of B. burgdorferi. To yield results applicable to the field situation, it was essential to mimic the natural system as closely as possible (Randolph \& Nuttall, 1994). Four sheep were taken from the fell in late May 1995, when they would have been naturally exposed to high tick infestation levels (including ticks infected with $B$. burgdorferi) during May (see below). Any naturally attached and engorged nymphs were collected and diagnosed for B. burgdorferi infection by PCR. The sheep were penned in a farm building and infested with unfed ticks contained within chambers. The chambers, made of $1 \mathrm{~cm}$ diameter neoprene rings covered with gauze, were glued to the clipped left sub-lumbar fossa region of each ewe. Each ewe received 1 chamber (A) and 2 of the ewes (1 and 3) received an additional chamber $(\mathrm{B})$ with its centre $10 \mathrm{~cm}$ from the first chamber. Unfed ticks were collected from the fell in May, where they would have gained a normal intensity of $B$. burgdorferi infection via the natural route, and so they were assumed to be infected according to the prevalences established from field observations (Table 2); consistent with this, none of a random sample of 30 nymphs was infected. Batches of 25 nymphs and 30 larvae were placed in each chamber on each of days $0,5,10,15$ and 20 of the experiment and, in addition, 10 adult females and 10 adult males were added to chamber B on days 0,5 , and 10. Detached engorged ticks were collected daily from the chambers and diagnosed for $B$. burgdorferi infection by PCR; negative controls were included at a rate of 2 per 3 tick samples.

\section{Statistical analyses}

Data for monthly counts of tick infestations were analysed by ANOVA with log transformation using GLIM (NAG Ltd, Oxford, UK) and standard model checking procedures (McCulloch \& Nelder, 1989). Differences in infection prevalence between methods of tick examination, site, years, months, tick stage and age of sheep were compared by a model (GLIM, NAG Ltd, Oxford, UK) prepared using binary errors (Cox, 1970).

\section{RESULTS}

\section{Tick-host interactions and seasonal dynamics}

Both the numbers of ticks questing for hosts on the vegetation (Ogden, 1995) and feeding on the sheep showed a bimodal seasonal pattern, with activity confined to March-September and peaks in May and September (Fig. 1). This bimodality was significant for nymphs and adults $(t=3 \cdot 82, P<0 \cdot 01$ and $t=4 \cdot 1, P<0 \cdot 001$ respectively), with a larger peak of nymphs in May than in September $(t=4 \cdot 5$, $P<0 \cdot 001)$. For larvae the second peak in September was non-significant. Lambs carried similar numbers of adult ticks $(\mathrm{F}=0 \cdot 05)$, but significantly fewer larvae and nymphs (D.F. $=99, \mathrm{~F}=14 \cdot 4, P<0.001$ and $\mathrm{F}=4 \cdot 46, P<0 \cdot 025$ respectively) than did ewes.

Over the whole year, only 19 rodents (discounting recaptures on the second day of each month's trapping) were trapped on the fell and 96 in the woodland (Table 1), comprising predominantly Clethrionomys glareolus (bank vole) and Apodemus sylvaticus (wood mouse) and also 5 Microtus agrestis (field vole) from the fell. The estimated densities (Fig. 2) were up to $7 /$ ha on the fell throughout the year and between 2/ha in May and 16/ha in the autumn in the woodland. This is far lower than the rodent densities typical of British woodlands (dotted line on Fig. 2 for comparison). Of the trapped rodents, only 12 were infested by I. ricinus, and these carried a total of 32 ticks, exclusively larvae (Table 1). The mean levels of infestation of rodents by larvae was higher on the fell than in the woodland, corresponding with the ca. 4-fold greater densities of questing immature ticks on the fell (peaks of up to 200-450 larvae and 40-120 nymphs/100 $\mathrm{m}^{2}$ ) than in the woodland (up to 10-100 larvae and 10-13 nymphs $/ 100 \mathrm{~m}^{2}$ ). Infestations on rodents followed the bimodal seasonal pattern seen on the vegetation and on sheep, and only in May and September were 5 rodents seen to feed more than a single larva, up to 5 , with 1 exceptional infestation of 12 larvae in the woodland. 
Table 1. The total number of rodents captured in 12 monthly trap sessions from February 1994 to January 1995, and the incidence of infestation by Ixodes ricinus, on the fell and in the adjacent relict woodland in Cumbria, England

\begin{tabular}{|c|c|c|c|c|c|c|}
\hline & \multicolumn{3}{|l|}{ Fell site } & \multicolumn{3}{|l|}{ Woodland site } \\
\hline & $\begin{array}{l}\text { No. of rodents } \\
\text { trapped }\end{array}$ & $\begin{array}{l}\text { No. of rodents } \\
\text { infested }\end{array}$ & $\begin{array}{l}\text { No. of ticks } \\
\text { counted }\end{array}$ & $\begin{array}{l}\text { No. of rodents } \\
\text { trapped }\end{array}$ & $\begin{array}{l}\text { No. of rodents } \\
\text { infested }\end{array}$ & $\begin{array}{l}\text { No. of ticks } \\
\text { counted }\end{array}$ \\
\hline $\begin{array}{l}\text { Apodemus } \\
\text { sylvaticus }\end{array}$ & 10 & 2 & 5 & 39 & 4 & 15 \\
\hline $\begin{array}{l}\text { Clethrionomys } \\
\text { glareolus }\end{array}$ & 4 & 2 & 7 & 57 & 4 & 5 \\
\hline $\begin{array}{l}\text { Microtus } \\
\text { agrestis }\end{array}$ & 5 & 0 & 0 & 0 & - & - \\
\hline Totals & 19 & 4 & 12 & 96 & 8 & 20 \\
\hline
\end{tabular}

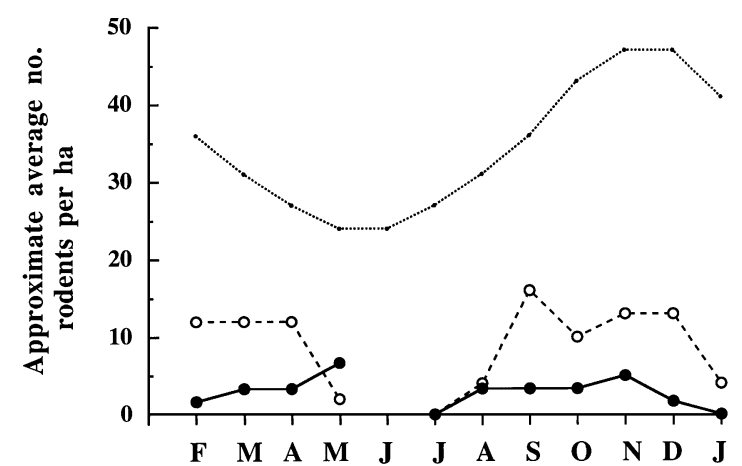

Fig. 2. The monthly densities of rodents (Apodemus sylvaticus, Clethrionomys glareolus and Microtus agrestis) on the fell $(\bigcirc)$ and in the woodland $(\bigcirc)$ of the Cumbrian moorland from February 1994 to January 1995. Typical densities of $A$. sylvaticus plus $C$. glareolus in British woodlands (Mallorie \& Flowerdew, 1994) are shown (dotted line) for comparison.

On the 16 ha of fell covered by the transects, only 3 species of resident birds were observed, meadow pipits (Anthus pratensis) (mean numbers counted, $9 \cdot 6 \pm 2 \cdot 4)$, skylarks (Alauda arvansis) $(10 \cdot 4 \pm 2 \cdot 0)$ and a single wheatear (Oenanthe oenanthe) (0.8), making a mean total of 1.25 birds of all species/ha.

\section{Identity and prevalence of $\mathrm{B}$. burgdorferi infection in ticks}

Only minor differences (4 base-pairs) in the sequences of $\mathrm{PCR}$ products derived from ticks collected on the study site (Ogden, 1995) and the reference strain $B$. burgdorferi s.s. strain B31 (Dykhuizen et al. 1993) suggest that the strain of $B$. burgdorferi circulating on the fell lies within the sensu stricto genospecies.

There was no significant difference in the prevalence of B. burgdorferi infection detected by PCR or immunofluorescence either in engorged nymphs $\left(12 / 73\right.$ and $13 / 72$ respectively, $\chi^{2}=0 \cdot 06$, D.F. $=1$, $P>0 \cdot 2)$ or in questing adults $(7 / 62$ and $5 / 50$ respectively, $x^{2}=1 \cdot 4$, D.F. $\left.=1, P>0 \cdot 1\right)$. The same pattern of increase in infection prevalence as the
Table 2. The mean infection prevalence (no. positive/no. examined and percentage) of Borrelia burgdorferi s.l. in questing Ixodes ricinus collected from the vegetation and engorged ticks collected from sheep from May to September in 1993 and 1994

(Prevalences in engorged ticks from ewes and lambs were similar.)

Chronology of amplification of infection $1993 \quad 1994$

\begin{tabular}{|c|c|c|}
\hline $\begin{array}{l}\text { Questing } \\
\text { larvae }\end{array}$ & $2 / 90^{a}=2 \cdot 2 \%$ & $1 / 132^{\mathrm{a}}=0.76 \%$ \\
\hline$\downarrow$ & $\times 4 \cdot 3 *$ & $\times 6.7$ \\
\hline $\begin{array}{l}\text { Engorged larvae } \\
\text { taken from sheep } \\
\downarrow\end{array}$ & $2 / 21^{b}=9 \cdot 5 \%$ & $2 / 39^{b}=5 \cdot 1 \%$ \\
\hline $\begin{array}{l}\text { Questing } \\
\text { nymphs }\end{array}$ & $1 / 73^{\mathrm{a}}=1 \cdot 4 \%$ & $1 / 221^{a}=0.45 \%$ \\
\hline$\downarrow$ & $\times 19 \cdot 2$ & $\times 33 \cdot 6$ \\
\hline $\begin{array}{l}\text { Engorged nymphs } \\
\text { taken from sheep } \\
\downarrow\end{array}$ & $7 / 26^{c}=26.9 \%$ & $18 / 119^{c}=15 \cdot 1 \%$ \\
\hline $\begin{array}{l}\text { Questing } \\
\text { adults }\end{array}$ & $8 / 36^{\mathrm{c}}=22 \cdot 2 \%$ & $12 / 112^{c}=10 \cdot 7 \%$ \\
\hline$\downarrow$ & $\times 1 \cdot 2$ & $\times 2 \cdot 0$ \\
\hline $\begin{array}{l}\text { Engorged adults } \\
\text { taken from sheep }\end{array}$ & $25 / 96^{\mathrm{d}}=26 \cdot 5 \%$ & $10 / 46^{\mathrm{d}}=21 \cdot 7 \%$ \\
\hline
\end{tabular}

* The figures in bold show the degree of amplification of $B$. burgdorferi at each feeding tick stage.

a Infection prevalences followed by the same letter do not differ significantly, according to a model (GLIM) prepared using binary errors.

tick's life-cycle proceeded was evident in both years (Table 2): the prevalence in questing adults was an order of magnitude higher than in either questing larvae or nymphs and there was a similarly greater prevalence in engorged nymphs taken from sheep than in unfed nymphs. Amplification of infection occurred to a much greater extent in nymphs feeding on sheep (20- to 30-fold) than in larvae (4- to 7-fold). 
Table 3. The prevalence of Borrelia burgdorferi infection in engorged

Ixodes ricinus ticks after experimental infestation of 4 ewes

(No ticks attached to ewes 3 and 4 , and no larvae attached to any sheep.)

\begin{tabular}{|c|c|c|c|c|c|}
\hline \multirow{3}{*}{$\begin{array}{l}\text { Sheep no.... } \\
\text { Chamber... } \\
\text { Tick stage... }\end{array}$} & \multicolumn{4}{|l|}{1} & \multirow{3}{*}{$\begin{array}{l}2 \\
\text { A } \\
\text { Nymphs }\end{array}$} \\
\hline & \multicolumn{2}{|l|}{ A } & \multicolumn{2}{|l|}{ B } & \\
\hline & Nymphs & Adults & Nymphs & Adults & \\
\hline \multicolumn{6}{|c|}{$\begin{array}{l}\text { Day no. of tick } \\
\text { introduction }\end{array}$} \\
\hline 0 & $0 / 1$ & - & $0 / 3$ & $0 / 0$ & $0 / 3$ \\
\hline 5 & $0 / 4$ & - & $0 / 3$ & $0 / 2$ & $0 / 1$ \\
\hline 10 & $0 / 2$ & - & $0 / 0$ & $1 / 4$ & $0 / 11$ \\
\hline 15 & $0 / 12$ & - & $0 / 13$ & - & $0 / 3$ \\
\hline 20 & $0 / 12$ & - & $5 / 17$ & - & $0 / 9$ \\
\hline Totals & $0 / 31$ & - & $5 / 36$ & $1 / 6$ & $0 / 27$ \\
\hline
\end{tabular}

Furthermore, transstadial maintenance of infection was lower from engorged larvae to unfed nymphs (on average $10 \%$ ) than from engorged nymphs to unfed adults $(77 \%)$. Subsequently, adult ticks feeding on sheep increased their infection prevalence by a small amount. In the laboratory, 12 out of 22 engorged larvae survived to moult to nymphs, but none was infected, whereas 21 out of 54 engorged nymphs moulted to adults, of which $4(19 \%)$ were infected (3 infections detected by PCR and 1 by immunofluorescence); these data accord with the field observations.

The recorded infection prevalence in engorged nymphs collected from sheep in 1994 showed significant seasonal variation (May, $7 / 50=14 \%$; July, 0/25 ; August, 0/6 ; September, 11/38 = 29\%) (May + September vs. July + August, $\chi^{2}=8 \cdot 9, P<$ $0 \cdot 01)$, with infection of feeding nymphs coinciding with high tick infestations of sheep (Fig. 1). Similarly, infected engorged nymphs were collected from $3 / 6$ ewes and 3/6 lambs in May, and 5/10 ewes in September, but from none of 8 ewes and 5 lambs during July and August. Infected larvae were collected from 1 ewe and 1 lamb in May, from 1 lamb in July and from 1 ewe in September.

\section{Results of transmission experiments}

No larvae introduced to any ewe, and only nymphs and adults introduced to ewes 1 and 2, fed successfully (Table 3 ). None of the nymphs which fed in chamber A on either ewe 1 or 2 became infected as determined by PCR. One adult female, introduced on day 10 to chamber $\mathrm{B}$ on ewe 1 and collected on day 18 , proved to be infected; 5 of 17 nymphs that fed in the same chamber from day 20 (collected on days 24 and 25) became infected. The infection prevalence in the total nymphs fed experimentally on ewes 1 and $2(5 / 94=5 \cdot 3 \%)$ was significantly greater than the mean level seen in questing nymphs in 1993 and $1994(2 / 294=0.68 \%$, Table 2$)\left(\chi^{2}=8 \cdot 64, P<\right.$
$0 \cdot 01)$. The infection prevalence in nymphs fed in chamber B after at least 1 adult had attached (5/33 $=15.2 \%$ ) was similar to the mean level seen in nymphs collected from wild sheep in 1993 and 1994 $(25 / 145=17 \cdot 2 \%$, Table 2$)$. On ewe 2 , infection was detected in 1/9 engorged nymphs found on the face of this ewe at the time of gathering from the fell (prior to experimentation); none of the 27 nymphs that were fed experimentally on the flank of this animal became infected, a result consistent with the absence of systemic B. burgdorferi infections in sheep under natural conditions.

\section{DISCUSSION}

Despite exhaustive efforts, very few wild vertebrates were detected on the moorland study site. Rodent densities were very low both on the fell and in the woodland (Fig. 2). Skylarks (ca. 0.65/ha) were half as abundant as were recorded on coastal dunes in Cumbria (0.67 breeding pairs/ha, Delius (1965)), but the density of meadow pipits (ca. $0 \cdot 6 /$ ha) was similar to that recorded in Wales (Seel \& Walton, 1979). This low density of rodents and birds is consistent with poor productivity and diversity of the plant communities in upland sheep-grazed pastures of north west England (Kelly \& Perry, 1990) and also typical of other parts of the UK, e.g. Wales and Scotland. Those wild hosts that were examined, the rodents, carried very few ticks (exclusively larvae). The birds were not examined, but Milne (1949) recorded low tick infestation levels, again almost exclusively larvae, on the same species in similar habitats (up to 13 larvae and $0 \cdot 6$ nymphs/bird in May). By comparison, sheep at densities of $1 /$ ha, doubling after lambing, each carried large numbers of larvae and nymphs in May and September (Fig. 1). Given the scarcity of alternative hosts (see Materials and Methods section), and the approximate relative densities of rodents, birds and sheep and their mean infestation levels, 
it is estimated that up to $80 \%$ of larval, > $99 \%$ of nymphal and all of the adult female I. ricinus on the fell fed on sheep. In the woodland adjacent to the fell, rodents and birds were more abundant, but sheep were excluded from mid-1993 onwards. Exclusion of sheep on such upland hills can cause a dramatic reduction in tick populations (Steele \& Randolph, 1985), and the low numbers of questing ticks in the woodland were presumably survivors from the previous years when sheep had grazed there and dropped engorged ticks of all stages. Therefore, any possible transfer of larval ticks by rodents and birds between habitats cannot explain the pattern of amplification of B. burgdorferi infection observed on the fell in this study.

Rather, the field observations indicate that sheep can maintain enzootic cycles of B. burgdorferi in the virtual absence of alternative hosts. Furthermore, the enzootiological pattern is strikingly different from that of previously studied foci of B. burgdorferi infection in several respects. First, very much less amplification of infection occurred during the feeding of larvae than the feeding of nymphs. This contrasts with patterns previously reported from woodlands, where amplification occurs principally as larvae feed on rodents (Lane et al. 1991; Matuschka et al. 1993) including squirrels (Randolph \& Craine, 1995). This was exacerbated by the low efficiency of transstadial maintenance of infection from larvae to nymphs, similar to that observed by Monin, Gern \& Aeschlimann (1989), so that questing nymphs were no more highly infected than were questing larvae (ca. $0 \cdot 5-2 \%$ for both stages), but questing adults were significantly more highly infected (11-22\%). Whatever contribution rodents may be making to transmission cycles of $B$. burgdorferi here, their very low population density and the tiny fraction of the exclusively larval tick population that they feed cannot account for this pattern. Furthermore, if the low infection prevalence in questing nymphs were due not to poor transstadial maintenance of infection, but rather to large numbers of larvae feeding on other unidentified vertebrates that were unable to amplify $B$. burgdorferi infection in these feeding larvae, such hosts could not contribute to the maintenance of $B$. burgdorferi cycles.

Secondly, infection of nymphs feeding on sheep was recorded only in May and September, when sheep were heavily infested with ticks. This is distinct from seasonal variation in infectivity of wild rodent populations to ticks, which is attributed to seasonal variation in both age structure of the host population and exposure of these short-lived hosts to infective ticks (Mather et al. 1989; Humair et al. 1993; Talleklint, Jaenson \& Mather, 1993). In this study, ewes, which had been exposed to tick-borne infections for at least 4 years on this site, and 1 month-old lambs were equally infective to feeding nymphs.
Both these unusual facets of B. burgdorferi transmission suggest that sheep do not develop systemic infections. If they did, they would be expected to transmit infections equally to all tick stages which feed on them at any time of the year. This raises the possibility that feeding nymphs were infected via an alternative transmission route now recognized for an increasing range of tick-borne infections, including Lyme disease spirochaetes: uninfected ticks may acquire a non-systemic infection, one that is limited to those parts of the host's body where ticks are feeding, by co-feeding in time or space with infected ticks (Jones et al. 1987; Gern \& Rais, 1996; Randolph, Gern \& Nuttall, 1996).

The spatial and temporal pattern of infection resulting from the transmission experiments reveals that adult ticks are indeed capable of transmitting $B$. burgdorferi to co-feeding nymphs via sheep. Only those nymphs that fed at the skin site where an infected adult tick had recently fed became infected; nymphs feeding previously at this site, or at any time on an adjacent separated (by at least $9 \mathrm{~cm}$ ) region of skin, remained uninfected, demonstrating that at no stage was the sheep systemically infected. It appears therefore, that the infected adult tick was capable of inducing an infection in the skin, local to its feeding lesion, from which subsequently feeding nymphs could acquire infection. Statistically less likely is the possibility that 1 of the 5 infected nymphs was the source of infection for the other 4 feeding nymphs; even if this did occur, transmission was clearly nonsystemic. Although these results come from a single replicate (due to logistical difficulties), the statistically significant results from the large number of ticks and the corresponding field data, demonstrate unequivocally that sheep support transmission of a non-systemic infection between co-feeding ticks. A similar phenomenon has been demonstrated in the laboratory, showing that B. burgdorferi can be transmitted between ticks co-feeding on laboratory mice before the establishment of a systemic infection (Gern \& Rais, 1996). Furthermore, the detection of B. burgdorferi infection in the skin of wild Japanese Sika deer only where clusters of nymphal $I$. persulcatus ticks were feeding, and the much higher infection prevalence in these feeding ticks $(81 \%)$ than in unfed questing ticks $(16 \%$ ) (Kimura et al. 1995), is consistent with amplification of infection by localized transmission to co-feeding ticks. The pattern of transmission involving sheep is, however, unusual, but can be partly explained by the immune response of vertebrates to $B$. burgdorferi.

The presence of host serum antibodies to certain Borrelia antigens significantly reduces transmission efficiency both to and from ticks (Fikrig et al. 1990; Schaible et al. 1993; Gern, Schaible \& Simon, 1993; Gern et al. 1994; Kurtenbach et al. 1994). Not surprisingly, all 4 ewes used in the transmission studies were immune to B. burgdorferi (Ogden, 
1995), and sera from $86 \%$ of 43 sheep (including lambs) sampled from March to October showed responses to $18-34 \mathrm{kDa} \quad B$. burgdorferi-specific proteins (ibid), while some of these sheep transmitted infection to nymphs during May and September. Infection was therefore not eliminated from ticks feeding on these immune sheep, as can occur in mice (Fikrig et al. 1992). The presence of specific immunoglobulins (Lovrich et al. 1993) might nevertheless explain the absence of systemic B. burgdorferi infection in sheep. The mechanism by which immune sheep support localized non-systemic transmission in ticks is unknown, but may involve the immunomodulatory properties of tick saliva (Titus \& Ribeiro, 1990). Such modulatory effects, presumably evolved to facilitate blood-feeding, enhance the efficiency of transmission of arboviruses (Jones $e t$ al. 1992; Labuda et al. 1993), even via an immune host (Labuda et al. 1997).

If local and transient immunosuppression induced by tick saliva enables immune sheep to support nonsystemic transmission to ticks, the greater amplification at the nymphal, rather than the larval, feeding stage can be explained by the partially overlapping spatial separation of ticks on sheep; successive stages are concentrated on increasingly high parts of the body and head, with $55 \%$ of nymphs, but only $10 \%$ of larvae, feeding alongside adults (Ogden, Hails \& Nuttall, 1997). Within these body regions, ticks of each stage habitually attach at sites where the hair is short or sparse, resulting in highly aggregated spatial distributions. The key rôle of tick saliva-induced immunomodulation of the feeding lesion in B. burgdorferi transmission, particularly if dose dependent, would also explain the field observation that infection of nymphs occurred only during periods of peak tick infestation on sheep, when the frequency of tick bites is maximal and the spatial separation of co-feeding ticks is minimal.

The addition of a bacterium to the wide range of viruses now known to be transmissable between cofeeding ticks in the absence of a systemic host infection, indicates that such a transmission mechanism may occur more frequently in nature than hitherto suspected (Randolph et al. 1996). The data presented here demonstrate that non-systemic transmission does indeed occur naturally in the wild and has a very significant epidemiological effect, namely the maintenance of Lyme borreliosis cycles in habitats dominated by sheep.

N.H.O. is grateful to the BBSRC for a Veterinary Research Fellowship (VRF19). S.E.R. was supported by the Royal Society and the Wellcome Trust during this work. NERC provided facilities for laboratory analysis. We are grateful to Drs Klaus Kurtenbach, Rosie Hails and Ernie Gould for advice and comments on the manuscript. We thank the farmers in Cumbria for their cooperation. Experimental sheep were handled under licence in accordance with the British Home Office regulations.

\section{REFERENCES}

CORBET, G. B. \& SOUTHERn, H. N. (1977). The Handbook of British Mammals, 2nd Edn. Blackwell, Oxford.

Cox, D. R. (1970). Analysis of Binary Data. Monographs on Statistics and Applied Probability. Chapman \& Hall, London.

CRaine, N. G., NUtTall, P. A., Marriott, A. C. \& RANDOLPH, S. E. (1997). Rôle of grey squirrels and pheasants in the transmission of Borrelia burgdorferi sensu lato, the Lyme disease spirochaete, in the U.K. Folia Parasitologica 44, 155-160.

CRaine, N. G., RANDOlph, S. E. \& NUtTall, P. A. (1995). Seasonal variation in the rôle of grey squirrels as hosts of Ixodes ricinus, the tick vector of the Lyme disease spirochaete, in a British woodland. Folia

Parasitologica 42, 73-80.

CRAmp, s. (1988). The Birds of the Western Palearctic. Volume V, Tyrant Flycatchers to Thrushes. Oxford University Press, Oxford.

DELiUs, J. D. (1965). A population study of skylarks Alauda arvensis. Ibis 107, 466-492.

DYKhuisen, D. E., POLin, D. S., DUNN, J. J., Wilske, B., PREAC-MURSIC, V., DATTWYLER, R. J. \& LUFT, B. J. (1993). Borrelia burgdorferi is clonal: implications for taxonomy and vaccine development. Proceedings of the National Academy of Sciences, USA 90, 10163-10167.

FIKRIG, E., BARTHOLD, S. W., KANTOR, F. S. \& FLAVELL, R. A. (1990). Protection of mice against the Lyme disease agent by immunization with recombinant OspA. Science 250, 553-556.

FIKRIG, E., TELFORD, S. R., BARTHOLD, S. W., KANTOR, F. S., SPIElman, A. \& FlaVEll, R. A. (1992). Elimination of Borrelia burgdorferi infection from vector ticks feeding on OspA-immunized mice. Proceedings of the National Academy of Sciences, USA 89, 5418-5421.

GERN, L. \& RAIS, O. (1996). Efficient transmission of Borrelia burgdorferi between cofeeding Ixodes ricinus ticks (Acari: Ixodidae). Fournal of Medical Entomology 33, 189-192.

GERN, L., RaIs, O., CAPIAU, P., HaUSer, P., LOBET, Y., SIMOEN, E., VOET, P. \& PÊTRE, J. (1994). Immunization of mice by recombinant OspA preparations and protection against Borrelia burgdorferi infection induced by Ixodes ricinus bites. Immunology Letters 39, 249-258.

GeRn, L., SChaible, U. E. \& Simon, M. M. (1993). Mode of inoculation of the Lyme disease agent Borrelia burgdorferi influences infection and immune responses in inbred strains of mice. Fournal of Infectious Diseases 167, 971-975.

GRAY, J. S. (1991). The development and seasonal activity of the tick Ixodes ricinus: a vector of Lyme borreliosis. Review of Medical and Veterinary Entomology 79, 323-333.

GURNELL, J. \& FLOWERDEW, J. R. (1990). Live trapping small mammals; a practical guide. Mammal Society Publication No. 3.

GUY, E. \& STANEK, G. (1991). Detection of Borrelia burgdorferi in patients with Lyme disease by the polymerase chain reaction. Fournal of Clinical Pathology 44, 610-611.

humair, P. F., TURRAin, N., AESChlimanN, A. \& GERN, L. (1993) Borrelia burgdorferi in a focus of Lyme 
borreliosis-epizootiologic contribution of small mammals. Folia Parasitologica 40, 65-70.

JAEnson, T. G. T. (1991). The epidemiology of Lyme borreliosis. Parasitology Today 7, 39-45.

JAENSON, T. G. T. \& TÄLLEKLINT, L. (1992). Incompetence of roe deer as a reservoir of the Lyme disease spirochaete. Fournal of Medical Entomology 29, 813-817.

Jones, L. D., Davies, C. R., STEele, G. M. \& Nuttall, P. A. (1987). A novel mode of arbovirus transmission involving a nonviraemic host. Science 237, 775-777.

JONES, L. D., HODGSON, E., Williams, T., HigGs, S. \& NutTall, P. A. (1992). Saliva-activated transmission (SAT) of Thogoto virus: relationship with vector potential of different haematophagous arthropods. Medical and Veterinary Entomology 6, 261-265.

KELly, P. G. \& PERRY, K. A. (1990). Wildlife Habitat in

Cumbria. Research and Survey in Nature Conservation, No. 30.

KIMURA, K., ISOGAI, E., ISOGAI, H., KAMEWAKA, Y., Nishikawa, T., IShit, N. \& FUjiI, N. (1995). Detection of Lyme disease spirochaetes in the skin of naturally infected wild Sika deer (Cervus nippon yesoensis) by PCR. Applied and Environmental Microbiology 61, 1641-1642.

kurtenbach, K., Carey, D., hoodless, a., Nuttall, P. A. \& RANDOLPH, S. E. (1997). Competence of pheasants as reservoirs for Lyme disease spirochetes. Fournal of Medical Entomology (in the Press).

Kurtenbach, K., DiziJ, A., SEITZ, H. M., MARGos, G., MOTER, S. E., KRAMER, M. D., WALLICH, R., SCHAIBLE, U. E. \& SIMON, M. (1994). Differential immune responses to Borrelia burgdorferi in European wild rodent species influence spirochaete transmission to Ixodes ricinus L. (Acari; Ixodidae). Infection and Immunity 62, 5344-5352.

LABUda, M., JONES, L. D., Williams, T. \& NUtTall, P. A. (1993). Enhancement of tick-borne encephalitis virus transmission by tick salivary gland extracts. Medical and Veterinary Entomology 7, 193-196.

LABUDA, M., KOZUCH, O., ZUFFOVA, E., ELECKOVA, E., Hails, R. S. \& NUTTALl, P. A. (1997). Tick-borne encephalitis virus transmission between ticks feeding on specific immune natural rodent hosts. Virology (in the Press).

LANE, R. S., PiEsMan, J. \& BURgdorfer, w. (1991). Lyme Borreliosis: relation of its causative agents to its vectors and hosts in north America and Europe. Annual Review of Entomology 36, 587-609.

LiVESley, M. A., CAREY, D., GERN, L. \& NUTTAll, P. A. (1994). Problems of isolating Borrelia burgdorferi from ticks collected in United Kingdom foci of Lyme disease. Medical and Veterinary Entomology 8, 172-178.

LOVRICH, S. D., CALlister, S. M., LIM, L. C. L. \& SCHELl, R. F. (1993). Seroprotective groups among isolates of Borrelia burgdorferi. Infection and Immunity 61, 4367-4374.

MALLORIE, H. C. \& FLOWERDEW, J. R. (1994). Woodland small mammal population ecology in Britain: a preliminary review of the Mammal Society survey of wood mice Apodemus sylvaticus and bank voles Clethrionomys glareolus, 1982-87. Mammal Review 24, $1-16$.
MATHER, T. N., WILSON, M. L., MOORE, S. I., RIBEIRO, J. M. C. \& SPIElman, A. (1989). Comparing the relative potential of rodents as reservoirs of the Lyme disease spirochaete (Borrelia burgdorferi). American Fournal of Epidemiology 130, 143-150.

MATUSChKa, F.-R., HEILER, M., EILFERT, H., FISCHER, P., LOlHTer, H. \& SPIElman, A. (1993). Diversionary role of hoofed game in the transmission of Lyme disease spirochaetes. American Fournal of Tropical Medicine and Hygiene 48, 693-699.

MCCUlloch, P. \& NELDER, J. A. (1989). Generalised Linear Models, 2nd Edn. Chapman \& Hall, London.

Milne, A. (1947). The ecology of the sheep tick, Ixodes ricinus $\mathrm{L}$. The infestations of hill sheep. Parasitology 38, $34-49$.

Milne, A. (1949). The ecology of the sheep tick, Ixodes ricinus L. Host relationships of the tick. Part 2. Observations on hill and moorland grazings in northern England. Parasitology 39, 173-196.

MONIN, R., GERN, L. \& AESCHLIMANN, A. (1989). A study of the different modes of transmission of Borrelia burgdorferi by Ixodes ricinus. Lyme Borreliosis II. Zentralblatt Bakteriologie 18 (Suppl.), 15-20.

o'Connell, s. (1995). Lyme disease in the United Kingdom. British Medical Fournal 310, 303-308.

ogden, N. H. (1995). The epizootiology of Lyme disease in upland habitats of north west England. D.Phil. thesis, University of Oxford.

Ogden, N. H., CARTER, S. D. \& NUTtall, P. A. (1994). Evidence for the transmission of the Lyme disease spirochaete to sheep in Cumbria. Veterinary Record 135, 383-384.

OGDEN, N. H., Hails, R. S. \& NUTTALl, P. A. (1997). Interstadial variation in the site of attachment of Ixodes ricinus (L) ticks to sheep. Experimental and Applied Acarology (in the Press).

PEARSAll, w. H. \& PENnington, w. (1989). The Lake District, Collins New Naturalist Series, Bloomsbury Books, London.

POSTIC, D., ASSOUs, M., GRIMONT, P. A. D. \& BARANTON, G. (1994). Diversity of Borrelia burgdorferi sensu lato evidenced by restriction fragment polymorphism of $r r f(5 \mathrm{~S})-r r l(23 \mathrm{~S})$ intergenic spacer amplicons. International Fournal of Systematic Bacteriology 44, $743-752$

RANDOLPH, S. E. \& CRAINE, N. G. (1995). General framework for comparative quantitative studies on transmission of tick-borne diseases using Lyme borreliosis in Europe as an example. Fournal of Medical Entomology 32, 765-777.

RANDOLPh, S. E., GERN, L. \& NUTTAll, P. A. (1996). Cofeeding ticks: epidemiological significance for tickborne pathogen transmission. Parasitology Today 12, 472-479.

RANDOLPH, S. E. \& NUTTALl, P. A. (1994). Nearly right or precisely wrong? Natural versus laboratory studies of vector-borne diseases. Parasitology Today 10, $458-462$.

Rodwell, J. S. (1994). British Plant Communities, Volume 1: Woodlands and Scrub. Cambridge University Press, Cambridge.

SChaible, U. E., Wallich, R., KRamer, M. D., NERZ, G., STEhle, T., MUSETEANU, C. \& SIMON, M. M. (1993). Protection against Borrelia burgdorferi infection in 
SCID mice is conferred by pre-sensitised spleen cells and partially by $\mathrm{B}$ cells but not $\mathrm{T}$ cells alone.

International Immunology 6, 671-681.

SEel, D. C. \& WALTON, K. C. (1979). The numbers of meadow pipits Anthus pratensis on mountain farm grassland in North Wales in the breeding season. Ibis 121, 147-164.

STEELE, G. M. \& RANDOLPH, S. E. (1985). An experimental evaluation of conventional control measures against the sheep tick, Ixodes ricinus (L.) (Acari: Ixodidae). I. A unimodal seasonal activity pattern. Bulletin of Entomological Research 75, 489-499.

TÄLlEKLINT, L., JAENSON, T. G. T. \& MATHER, T. N. (1993). Seasonal variation in the capacity of the bank vole to infect larval ticks (Acari: Ixodidae) with the Lyme disease spirochete, Borrelia burgdorferi. Fournal of Medical Entomology 30, 812-815.

TELFORD, S. R., MATHER, T. N., MOORE, S. I., WILSON, M. I. \& SPIElMaN, A. (1988). Incompetence of deer as reservoirs of the Lyme disease spirochaete. American Fournal of Tropical Medicine and Hygiene 39, 105-159.

TITUS, R. G. \& RIBEIRO, J. M. C. (1990). The role of vector saliva in transmission of arthropod-borne disease. Parasitology Today 6, 157-160.

WILSON, M. L., TELFORD, S. R., PIESMAN, J. \& SPIElMAN, A. (1988). Reduced abundance of immature Ixodes dammini (Acari: Ixodidae) following elimination of deer. Fournal of Medical Entomology 25, 224-228. 